\title{
https://doi.org/10.48009/1_iis_2006_62-66 \\ INTEGRATING BUSINESS ACUMEN WITH IT SKILLS IN THE SAME COURSE: A CASE STUDY WITH IMPLICATIONS FOR INCREASING IS PROGRAM ENROLLMENTS
}

\author{
Wayne Huang, Ohio University, huangw@ohio.edu \\ Raymond Frost, Ohio University, frostr@ohio.edu \\ Sean McGann, Ohio University, mcgann@ ohio.edu
}

\begin{abstract}
IS program enrollments have been significantly decreasing in the last 3 years nationwide. This paper presents a case study to address this important issue by integrating business acumen with IT skills in course design. Students in the integrated course express greater satisfaction with this course compared to other non-integrated courses. We found that students master business skills more readily, and enjoy them more, when they are integrated with technical skills. Furthermore, we have evidence that they are better positioned in the job market. Both of these factors may help explain the increased enrollments of our IS program. In addition, students develop business analysis and technical design skills which are difficult to outsource.
\end{abstract}

Keywords: IS Pedagogy, Integrated Curriculum, Enrollment

\section{INTRODUCTION}

IS program enrollments have been significantly decreasing in the last 3 years nationwide. For example, the enrollment of the Information and Management Sciences program of University of Florida decreased $66 \%$ in 2004 as compared to 2001, and our own MIS program decreased $72 \%$ from 2001 to 2004. For many IS faculty and department chairs, how to control this enrollment decrease is not just a key issue for future development, but a key issue for survival.

This paper reports a case study on how the faculty of an MIS department of a large public university in the Midwest worked out effective strategies for dealing with decreased enrollments. The primary thrust of our strategy was the revision of our curricula to integrate business acumen with IT skill sets in all courses offered in our MIS program. Using a case study, we offer a specific example of how we designed and integrated two courses into one offering, and detail how the integrated course is taught. The positive outcomes of the integrated course curricula in terms of increasing IS program enrollment as well as improving students' learning performance are reported, and the findings of this case study provide insights and suggestions for other IS educators in their efforts to revise IS curricula to increase their enrollments and enhance student learning.

\section{LITERATURE REVIEW}

\section{Prior Relevant Studies}

Most current IS courses are designed and taught separately without integrated content across courses. Students learn separate knowledge and skills in different IS courses and frequently don't see the integration between different classes across the curricula to form a holistic IS skill set. They also frequently do not see the application of what they are learning to the business environment. As a result, IS students may have difficulties tackling real business problems. Such problems may not necessarily be complicated. They simply require knowledge and skills that should be acquired through an integrated design. Our experience shows that such an integrated understanding of IS skills is not promoted in current IS curricula.

Medical schools in the US have been leaders in addressing the challenge of integrating courses to foster holistic learning $[3,5,7,9]$ through interdisciplinary integration of the humanities, clinical medicine, and basic sciences.

Some medical schools adopted problem-based learning (PBL) to enhance student-centered, interactive and integrated learning through intensive small group tutorials, which were introduced by McMaster University in Canada in 1969 [2]. In medical education, commonly encountered medical problems serve as the primary focus of, and stimulus for, learning.

Integrated learning has also been adopted in other disciplines such as in engineering [1] by integrating 
engineering knowledge with societal and environmental factors [8].

Thus, IS, as a relatively new discipline, can learn from those more established disciplines such as medicine and engineering to integrate IS courses in order to help students better prepare for new challenges in the current job market.

\section{Relevant Theory on Integrated Learning}

There are two dominant learning theories in the education field: the objectivist and constructivist models of learning. The former posits that there is an objective reality and that the goal of learning is to understand this reality and modify behavior accordingly $[4,6]$. The latter posits that there is not such an objective reality independent of a learner's mind. Rather than transmitted, knowledge is created, or constructed, by each learner [6].

Constructive learning calls for learner-centered instruction: learners are assumed to learn better when they are encouraged to discover things themselves rather than when they are told or instructed.

Based on the constructivist theory of learning, integrating MIS courses may help students better understand the links and connections between those courses. Students are more likely to see the big and correct picture, which will in turn help them better construct meaning from learning materials. Therefore, according to the constructivist's learning theory, integrating separate courses can help students learn better. Given the cross-disciplinary nature of IS programs, the integration of IT skills with business acumen seems to be natural and important.

\section{CASE STUDY}

\section{Background of the Case Study}

Prior to integrating the courses, a survey was conducted by MIS faculty to determine how students felt about the impact of IT outsourcing on the IT job market when they graduated. The findings show that (1) some students were concerned about the negative impact of outsourcing on the IT job market while many other students were not very sure (see Figure 1); (2) $17 \%$ of the surveyed students did think of dropping the MIS major due to the fear of IT offshore outsourcing; and (3) many students found out about the possible negative impact of IT outsourcing on the job market from their parents, friends and the news, so most of them didn't do research themselves on this issue (in our estimation, that was why they were not very sure about the issue. They were admittedly easily affected by their parents, friends and mass media news), as shown in Figure 2.

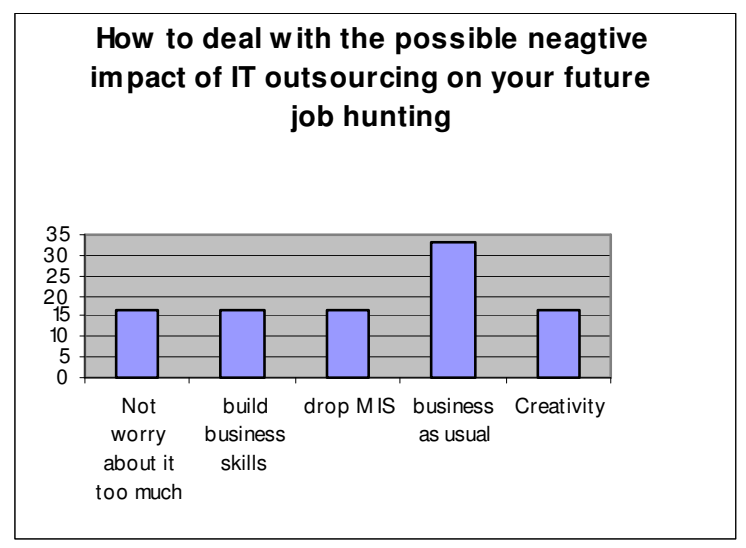

Figure 1. Negative Impact of IT Outsourcing

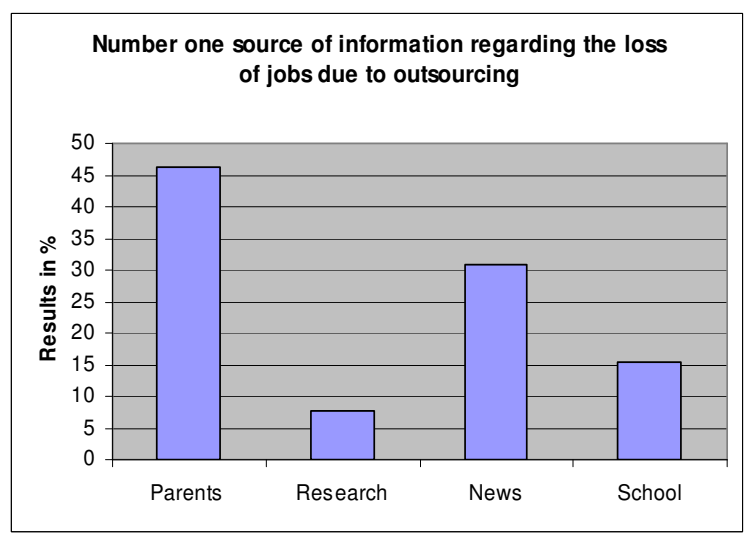

Figure 2. Source of Info about IT Outsourcing

Further, an examination of outsourcing research literature shows that outsourcing affects some IT jobs more than others. Programming and purely technical work that can be done remotely are affected much more than other types of IT jobs that are more tightly linked with business strategies and/or processes, such as IT consulting and project management, etc. (see, for example, www.Reuters.com, July 29, 2003).

Therefore, one strategy to deal with the cause of enrollment decreases is to revise the IS curricula to better prepare students for the job market by focusing on developing skills that could not be offshored. Efforts were made to integrate business acumen with IT skills in our curricula, with the goal of providing our MIS students with IS analysis, consulting and project management skills. In addition, we also encourage students to declare a double major (MIS and another business discipline) to further integrate their business skills with IT skills. 


\section{Integrated MIS Course Example}

The following section will describe how two separate courses: MIS 320 (systems analysis and design) and MIS 380 (database design) are designed into one integrated course which combines business acumen and IT skills. We also detail how it is taught in the classroom and students' perceptions of this integrated course.

Previously our curriculum model had two separate courses: MIS 320 (systems analysis and design), which emphasized business issues related to systems development; and MIS 380 (database design), which emphasized IT issues. These courses were taught by two different faculty members.

Following the same logic that IS strategy should be aligned with business strategy in a corporation, we aligned business acumen with IT skills in our new design for our MIS curricula.

Specifically, technical database content in the former MIS 380 (database) course was integrated with MIS 320 (systems analysis and design) based on the Systems Development Life Cycle (SDLC) framework (our central curriculum model) which is shown in Table 1.

Also, the whole integrated course was designed with a project-based focus on problem-solving and project management. The course has evolved over time. In its first iterations, on which this paper is based, the entire course was taught in the context of complete systems, with databases forming just one part of those systems. Over time we have seen that it is better to teach the database content first and then fold in complete systems later in the course.

In its current iteration, the first half of the course focuses on database design and development. Students are given business requirements and challenged to design, develop, and query a database that satisfies those requirements. This covers three stages of the SDLC. Work in the first half of the course is completed individually. The second half of the course broadens the focus to include the entire system (people, process, and technology) not just the database. Each week students are exposed to best practice systems development by invited speakers. These include students in the senior capstone course and professionals in the field. During this time students develop a system to support a fictional company offering exotic tours. The deliverables become much more in depth as reflected in the table above. Work in the second half of the course is completed in teams. Project management using MS Project is stressed. Student teams learn how to do business systems analysis, business process design, systems architecture design, systems navigation chart, screen prototypes, database design using ER diagrams, and actual implementation using ASP.Net.

Table 1. Road Map for IS Projects (SDLC)

\begin{tabular}{|c|c|}
\hline 1. & $\begin{array}{ll}\text { Current State Analysis (As-is system) } \\
\circ & \text { System Overview Report } \\
\circ & \text { As-is Use Case Diagram } \\
\circ & \text { Project management plan } \\
\circ & \text { Role \& Stake-holder analysis report and } \\
& \text { Known Issues List } \\
\circ & \text { People Issues } \\
\circ & \text { Requirements List } \\
\circ & \text { Modeling requirements using UML } \\
& \text { Activity Diagrams } \\
\circ & \text { Feasibility Study Report }\end{array}$ \\
\hline 2. & $\begin{array}{l}\text { Requirements Definition (future state: To-be } \\
\text { system) } \\
\circ \text { To-be use cases: through BPR/BPI/BPA } \\
\circ \text { To-be process flows } \\
\circ \quad \text { Signoff I }\end{array}$ \\
\hline 3. & $\begin{array}{ll}\text { Application Design } \\
\circ & \text { Functional design write-up } \\
\circ & \text { System architecture design diagram } \\
\circ & \text { SiteMap (Interface Design \& Description) } \\
\circ & \text { Screenshots and Backend description } \\
\circ & \text { Database design } \\
\odot & \text { Signoff II } \\
\end{array}$ \\
\hline 4. & 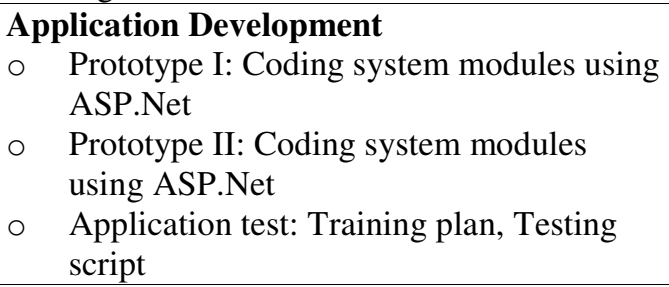 \\
\hline 5. & $\begin{array}{ll}\text { Implementation } \\
\circ & \text { Documentation: system \& user } \\
\circ & \text { Final demonstration } \\
\circ & \text { Knowledge transfer: training } \\
\circ & \text { Migration: Migration plan }\end{array}$ \\
\hline
\end{tabular}

The modeling and software tools used are UML modeling diagrams such as Use Case Diagrams, Activity Diagrams, State Transition Diagrams, Rational Rose software, MS Visio, Photoshop, MS Project, MS Access, and MS Visual Web Developer.

At the end of each phase, two teams are called upon to walk the class through their deliverables. At the end of the quarter, groups are required to wrap up their projects and submit final reports. 
After two quarters of teaching using the new integrated MIS 320/380 model, a survey was conducted to get students' feedback on the newly designed integrated course. Summary graphs of the survey findings are shown below.

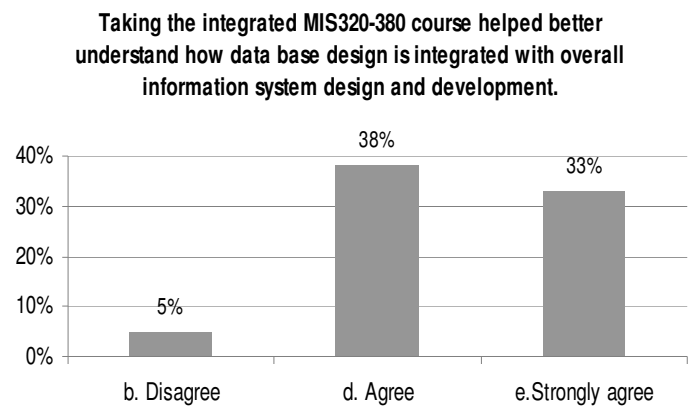

Figure 3. Integration of DB Design with Information Systems Design and Development

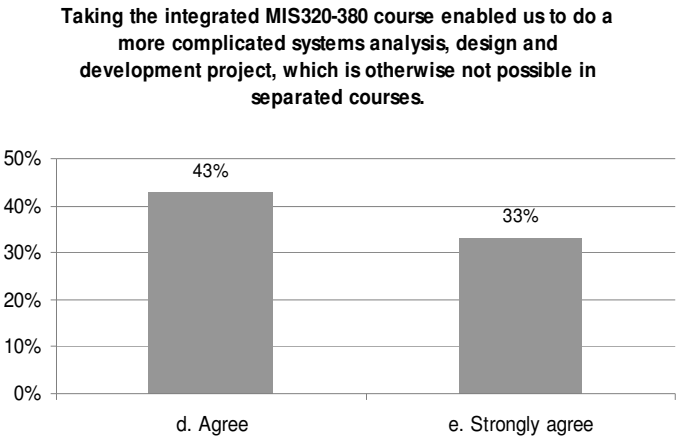

Figure 4. Ability to do More Complex Project

Taking the integrated MIS320-380 course helped us get a better feeling of the systems development process in reality than separated courses.

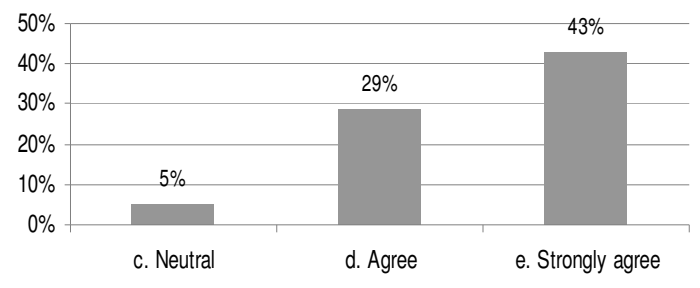

Figure 5. Better Feel for Systems Development Process
I learned more in the integrated course than in traditional separated courses.

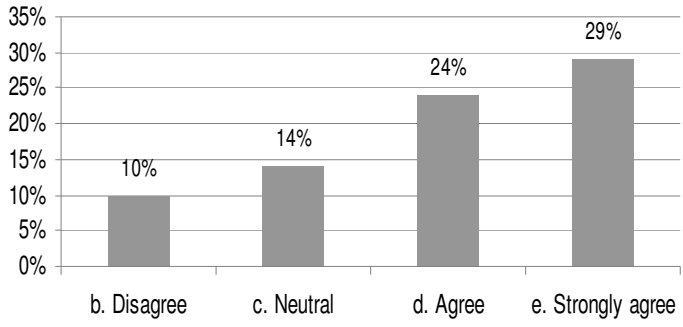

Figure 6. Increase in Learning

Further, after implementing the integrated MIS curricula, as well as some other effective measures taken by the MIS Department, our MIS enrollment increased $75 \%$ between 2003 and 2005, and course evaluations from MIS 320/380 increased from 3.9 to 4.3 (on a 5-point Likert scale).

\section{DISCUSSION AND IMPLICATIONS}

This case study explored an important issue faced by IS faculty and administrators: how to deal with IS program enrollment decrease by designing curricula which develop skills difficult to outsourcespecifically the integration of business acumen with IT skills. The strategy and actions taken have proven successful by contributing to our overall MIS enrollment increase and an upward trend in course evaluations.

Our integrated course model can be implemented by other IS programs that are facing the problem of enrollment decline. It is our hope that our case study will provide useful insights to assist our IS colleagues in effectively dealing with this problem.

\section{REFERENCES}

1. Geddam, A. (2003). Mechatronics for engineering education: Undergraduate curriculum. International Journal of Engineering Education, 19(4), 575-580.

2. Gwee, M.C.E. \& Tan, C.H. Problem-based learning in medical education: The Singapore hybrid. Journal of Annals Academy of Medicine Singapore, 30(4), 356-362.

3. Hudson, J.N. \& Tonkin, A.L. (2004). Evaluating the impact of moving from discipline-based to integrated assessment Medical Education, 38(8), 832-843. 
4. Jegede, O. J., Walkington, J., \& Naidu, S. (1995). An investigation into students' disposition to the use of objectives in distance learning materials. Educational Research, 37( 3), 293-304.

5. Lanzilotti, S. S., Finestone, A.J., Sobel, E., \& Marks, A.D. (1986). The practice integrated learning-sequence-Linking education with the practice of medicine. Adult Education Quarterly, 37(1), 38-47.

6. Leidner, D. E. , \& Jarvenpaa, S. L. (1995). The use of information technology to enhance management school education: A theoretical view. MIS Quarterly, 19(3), 265 - 291.
7. Maudsley, G. (May 2003). TI: The limits of tutors' comfort zones with four integrated knowledge themes in a problem-based undergraduate medical curriculum (interview study), Journal of Medical Education, 37(5), 417-423.

8. McCowan, J.D. \& Knapper, C.K. (2002). An integrated and comprehensive approach to engineering curricula, part one: Objectives and general approach. International Journal of Engineering Education, 18(6), 633-637.

9. Sefton, A.J. (1998). The future of teaching physiology: An international viewpoint. Journal of Advances In Physiology Education, 20(1), 5358. 